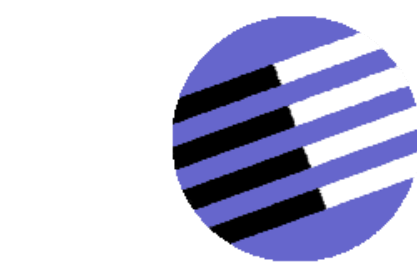

GOVERNANCE AND THE EFFICIENCY

OF ECONOMIC SYSTEMS

GESY

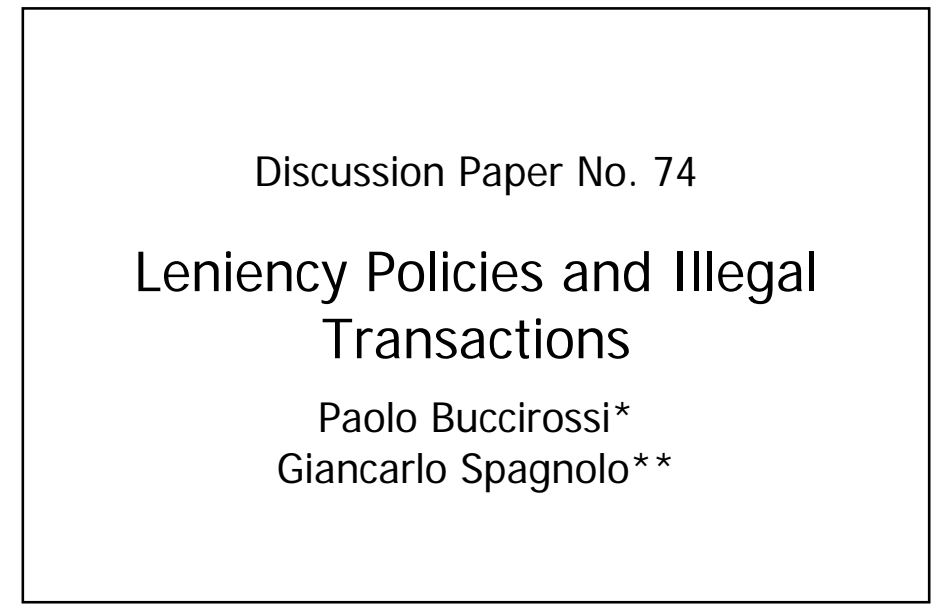

September 2005

*Paolo Buccirossi, Lear - Laboratorio di economia, antitrust, regolamentazione, E-mail: paolo.buccirossi@learlab.it **Giancarlo Spagnolo, Stockholm School of Economics, Consip Research Unit, and C.E.P.R. E-mail: giancarlo.spagnolo@tesoro.it or giancaspagnolo@yahoo.com

Financial support from the Deutsche Forschungsgemeinschaft through SFB/TR 15 is gratefully acknowledged. 


\title{
Leniency Policies and Illegal Transactions
}

\author{
Paolo Buccirossi ${ }^{1} \quad$ Giancarlo Spagnolo ${ }^{2}$
}

First version: October 1999

Final version: September 8, 2005

Forthcoming in the Journal of Public Economics

\footnotetext{
${ }^{1}$ Lear - Laboratorio di economia, antitrust, regolamentazione, E-mail: paolo.buccirossi@learlab.it

${ }^{2}$ Stockholm School of Economics, Consip Research Unit, and C.E.P.R. E-mail: giancarlo.spagnolo@tesoro.it or giancaspagnolo@yahoo.com.
} 


\begin{abstract}
We study the consequences of leniency - reduced legal sanctions for wrongdoers who spontaneously self-report to law enforcers - on sequential, bilateral, illegal transactions, such as corruption, manager-auditor collusion, or drug deals. It is known that leniency helps deterring illegal relationships sustained by repeated interaction. Here we find that - when not properly designed - leniency may simultaneously provide an effective governance mechanism for occasional sequential illegal transactions that would not be feasible in its absence.
\end{abstract}

\title{
JEL Classification: K42, K21
}

KEYWORDs: Amnesty, corruption, collusion, financial fraud, governance, hold up, hostages, illegal trade, immunity, law enforcement, leniency, organized crime, selfreporting, whistleblowers. 


\section{Introduction}

The economic and social costs of organized illegal transactions are enormous. Financial frauds, earning management schemes, firm/auditor and investment bank/analyst collusion have recently undermined the smooth operation of financial markets in more than one country. ${ }^{1}$ The direct and indirect costs of drugs, arms, toxic waste, and people trafficking are obvious and huge. Terrorism can also be seen as a form of organized crime. And even economists' traditional benevolence towards corruption, once seen as a way to overcome excessive regulation, has been heavily questioned by recent studies showing that corruption may reduce investment, financial development, and growth. ${ }^{2}$

Since illegal transactions involve at least two parties and require trust among them - their potential opportunism cannot be limited by court-enforced contracts one way law enforcement agencies traditionally fight them is undermining trust by shaping incentives to play one party against the other(s): ensuring that they find themselves in a situation as close as possible to a Prisoner's Dilemma. ${ }^{3}$ Law enforcers do this by awarding leniency - typically a reduction or cancellation of legal sanctions accompanied by protection from retaliation and related benefits - to wrongdoers that self-report helping to convict "the rest of the gang." Formal or informal exchanges of leniency against information are common in most world countries, and have been extensively and successfully used to fight Mafia, drug dealing and terrorism.

It is by now well known that on multi-agent criminal relationships sustained by repeated interaction leniency for self-reporting wrongdoers can have a particularly strong deterrence effect: Spagnolo (2000a, 2004) showed that leniency for undetected wrongdoers that spontaneously self-report could in principle costlessly deter all forms of organized crime enforced by reputational considerations, making the investigation activity redundant. To have such pervasive effects, however, leniency should not only reduce sanctions, it should also reward wrongdoers that spontaneously report and turn in their partners. Instead, in reality leniency is often "moderate": it only reduces or at most cancels legal sanctions against a self-reporting party (obvious examples are the US and EU Leniency Programs for cartels). The main reason why such policies often do not offer rewards to applicants appears ethical and political, as many people consider immoral to reward someone who acted illegally, and fear the lack of trust of an "informants' society", although rewards to whistleblowers are and have been

\footnotetext{
${ }^{1}$ Leading the US government to introduce the Sarbanes-Oxley Act which, among other things, reinforces protection of whistle-blowers.

${ }^{2}$ Bardhan (1997) offers an overview of the early literature; hundreds of economic papers have been published since then. Mauro's (1995) pioneering analysis estimates that a one standard deviation improvement in a country corruption index is associated with an increase in the investment rate by about 3 percent of GDP. Recent work on transition economies places corruption at the heart of their poor post-privatization performance (see e.g. Boycko et al. 1995; Johnson et al. 2002; Black et al. 2000; and Jones et al. 2000).

${ }^{3}$ From a theoretical point of view, the Prisoner's Dilemma game itself is perhaps the best known model of leniency in law enforcement: the sanctions for a prisoner that unilaterally confesses his crime are reduced to induce him to confess and prove guilty his former partner(s).
} 
successfully used in many situations. ${ }^{4}$

Moderate leniency may still produce significant benefits as it reduces law enforcement cost for individual crimes (Kaplow and Shavell, 1994), and may have deterrence effects on long term illegal relationships as it may facilitate prosecution (Motta and Polo, 2003), and increase both the incentives to defect and report and the "strategic risk" of entering an illegal arrangement (Spagnolo 2004). However, as it turns out, moderate leniency may also have puzzling side effects on occasional illegal transactions, which add a potential cost besides their just mentioned benefits.

Occasional sequential illegal transactions are extremely exposed to "governance" or "hold up" problems, because to constrain opportunistic behavior from the party delivering last, the party delivering first cannot normally rely upon explicit contracts enforced by an external system. ${ }^{5}$ We show that poorly designed leniency policies may solve this governance problem by inducing transacting parties to collect hard evidence on the illegal agreement and use it as a "hostage", threatening to report it to law enforcers in case of "hold up". A poorly designed/managed leniency policy may ensure that this threat is credible, so that all parties comply with the otherwise unfeasible occasional illegal exchange.

Williamson (1983) first discussed this "third way" by which parties may govern economic transactions and hold-up problems: transferring "hostages" between parties. ${ }^{6}$ An occasional sequential illegal exchange is a transaction in need of governance because the party delivering first risks being "held-up" by the one delivering last. The mechanism we uncover here is an example of this third form of governance, with the hard evidence on the illegal transaction playing the role of the hostage: the information is valueless in itself - as hostages typically are for the party that holds them but a party can credibly use it in response to hold-up to seek amnesty and punish the partner that did not deliver.

We model asymmetric bilateral sequential illegal transactions, like a corrupt deal between an entrepreneur or manager and a bureaucrat or auditor, where the existence/production of hard evidence on the illegal agreement, the sequence of the exchange, and the distribution of illegal gains are all endogenously chosen by the parties to ensure that the transaction can be implemented, given the legal framework. We characterize the effects of leniency under all parameter configurations, and find

\footnotetext{
${ }^{4}$ See Spagnolo (2006) for a discussion of historical and present examples. Rewards to whistleblowers may entail potential costs not analyzed in the present setting, including reduced trust in organizations and society, false reports aimed at capturing rewards, and courts increasing standards of proof. Aubert et al. (2004) and Buccirossi et al. (2005) analyze several potential costs of rewarding whistleblowers, but argue that the benefits stemming from the deterrence effects of appropriately designed rewards are likely to outweigh all these potential costs.

${ }^{5}$ We write "normally" because in some countries third parties like the Mafia or less obviously illegal networks partially solve these problems by taxing illegal transactions and offering "enforcement services", as discussed in Section 4.2.2 (see e.g. Gambetta, 1993; Gambetta and Reuter, 1995)

${ }^{6}$ The other two way of governing a transaction are of course explicit contracting and repeated interaction ("relational exchange").
} 
that the moderate forms of leniency frequently implemented in reality may indeed have a paradoxical side effect: they may provide an effective enforcement mechanism for occasional, sequential illegal transactions that would not be enforceable in their absence - nor in the absence of law enforcement altogether.

We mentioned that Kaplow and Shavell (1994) highlighted how the policy of offering a lenient treatment to wrongdoers that spontaneously self-report reduces the pool of individuals to monitor without reducing deterrence, thereby directly reducing law enforcement costs (see also Malik, 1993); and that when agents are risk averse, this policy also increases welfare by reducing the overall risk agents bear. Innes (1999a,b) stressed the value of the early remediation of damages from a crime that encouraging self-reporting entails. ${ }^{7}$ These analyses focus on the case of single wrongdoers committing isolated crimes, in the tradition of Becker (1968).

In a novel strand of literature, Motta and Polo (2003), Spagnolo (2000, 2004), Rey (2003), Aubert et al. (2004), Harrington (2005), and others analyse groups of organized wrongdoers who must govern/sustain internal cooperation (e.g. collusion) through self-enforcing illegal agreements, as illegal explicit contracts cannot be enforced by courts by definition. They show that the problem becomes then fundamentally different, dynamic, because repeated interaction or reputational concerns must be relied upon to govern internal opportunism; and that leniency deters organized crime - tightening "self-enforcing constraints" - by facilitating prosecution, increasing incentives to cheat on partners and report, protecting those who cheat and report from former partners' revenge, and increasing the "riskiness" of the criminal agreements. ${ }^{8}$

The present paper extends the analysis to occasional, asymmetric, sequential opportunities for illegal cooperation that cannot be governed by long term considerations, and highlights a potential perverse effect that awarding leniency to wrongdoers that self-report may have on these. Analogous negative effects are discussed by Spagnolo (2000b) in the context of multiunit procurement auctions, and by Ellis and Wesley (2002) in a differentiated dynamic oligopoly. Potential perverse effects of law enforcement instruments have been highlighted before, among others, by Mookherji and Png (1995), Livernois and McKenna (1999), and Boadway et al. (2002), but these effects are very different from the one we point out here, and concern sanctions rather than leniency.

Section 2 presents the simplest model we could think of to identify the alterations of individual incentives induced by a moderate leniency program that may implement sequential illegal transactions. Section 3 analyzes the model and presents the main results. Section 4 discusses extensions, tests the robustness of our results, and relates them to some existing literature, traditional arguments in favor of leniency, and reality. Section 5 briefly concludes.

\footnotetext{
${ }^{7}$ See also Innes (2000) and (2001).

${ }^{8}$ Fees and Walzl (2004) also address leniency with criiminal teams, but use a static model that fails to endogenize collusion. See Spagnolo (2006) for a survey of this burgeoning field.
} 


\section{The model}

For concreteness we phrase the model as a corrupt exchange between an entrepreneur and a bureaucrat, but everything could be restated in terms of an exchange of "favors" between an auditor and a manager, a deal between a drug producer and a drug retailer, or any other sequential illegal transaction. Therefore, the main results will be stated in more general terms.

The illegal transaction. There are two agents, a bureaucrat $(B)$ and an entrepreneur $(E)$. The entrepreneur has an investment opportunity with net present value $v>0$ that can be realized only if the bureaucrat performs an action $a$, illegal or contrary to his duty. To perform this action the bureaucrat may require compensation, a bribe $b$ with $0 \leq b \leq v \cdot{ }^{9}$ We assume that if the bureaucrat, by performing the illegal action, does not increase his monetary gain, he prefers to behave legally. Corruption is an illegal agreement between the bureaucrat and the entrepreneur according to which the former should do $a$ and the latter should pay $b$.

Evidence. The application of a leniency program and law enforcement in general require that some "hard evidence" on the illegal transaction exist. The existence of hard evidence may either result from the exchange itself or be deliberately produced by the parties (e.g. writing down and sign illegal agreements, taking pictures, or keeping any other records of meetings and decisions). To simplify and sharpen our result on the use of evidence as a 'hostage', we assume that absent an explicit decision by the agents to produce hard evidence on the agreement, no hard evidence exist. We also assume that once hard evidence is produced, both parties posses it and the law enforcers have the possibility to find it when auditing the agents and use it to convict them. If an agent directly reports the hard evidence to the law enforcers, then corruption is proved and agents are convicted/sanctioned with certainty. If the parties choose not to produce hard evidence, then they cannot be convicted for the illegal exchange. ${ }^{10}$

Law enforcement. At the end of the game, law enforcers audit agents with probability $\alpha$. If hard information is produced and agents are audited corruption is detected and parties are convicted. Therefore, the probability of conviction is $\alpha<1$. If hard information is not produced the probability of conviction is 0 .

The normal sanction for an agent $i$ proved guilty of corruption, $S_{i}$, consists in the confiscation of the illegal gain $(v, b)$, if any, plus a fine $F_{i}$, with $i=B, E$ and $F_{i}>0$.

\footnotetext{
${ }^{9}$ In the "drug deal" interpretation of the model, $v$ would be the net value of the transacion and $b$ the agreed price.

${ }^{10}$ These assumptions imply that the decision to use strategically a leniency program to implement an illegal transaction may entail a costly increase in the probability of conviction. This cost plays a role in the extension discussed in Section 4.2.2. A positive but smaller probability of being convicted when parties choose not to deliberately produce hard evidence, for example due to some hard evidence beying automatically generated by the illegal agreement and potentially collected by law enforcers, would make the model somewhat more cumbersome without changing any qualitative result.
} 
That is, $S_{i}=g_{i}+F_{i}$, where $g_{B} \in\{0, b\}$ and $g_{E} \in\{0, v\}$, depending on the stage of the exchange at which agents are discovered and sanctioned.

Leniency consists in reducing the sanction for a wrongdoer when this spontaneously denounces the illegal transaction and provides evidence sufficient to convict the other offender. We let $R F_{i}, i=B, E$, denote the reduced monetary fine for an agent $i$ that obtains leniency, with $R F_{i} \leq F_{i}$; and let $R S_{i}$ denote the overall reduced sanction, with $R S_{i}=R F_{i}+g_{i}$. Since we are taking $F_{i}$ for given, a "leniency program" (or leniency policy; "LP" from now on) is completely defined by the fine reductions for the two agents $\left(R F_{E}, R F_{B}\right)$. Of course, when $R F_{i}=F_{i}\left(R S_{i}=S_{i}\right)$ for all $i$ we are in the case of "no leniency."

LPs may well establish positive transfers (negative additional fines) $-R F_{i}>0$. Note, however, that even when the additional transfer is negative the overall reduced sanction $R S_{i}=R F_{i}+g_{i}$ remains positive as long as $-R F_{i}<g_{i}$.

We now define a Moderate Leniency Program (MLP).

Definition $1 A L P$ is a $M L P$ if the law enforcer never (i.e. at any possible final node of the game) pays a reward. Formally, $L P$ is a $M L P$ if $R F_{B} \geq 0$ and $R F_{E} \geq 0$.

Timing. Illegal transactions are carried out over time after the legislator has set the parameters of public law enforcement, agents have observed them and reached an agreement on bribe, sequence of exchange, and production of hard evidence.

The overall timing of the game is therefore as follows:

\begin{tabular}{cccc}
$t=0$ & $t=1$ & $t=2$ & $t=3$ \\
\hline $\mid$ & $\mid$ & $\mid$ & $\mid$ \\
Legislator sets & $\begin{array}{c}\text { Parties agree on } a, b, \\
\text { and production of } \\
F_{i} \text { and } R F_{i}\end{array}$ & $\begin{array}{c}\text { Transaction } \\
\text { takes place }\end{array}$ & $\begin{array}{c}\text { Law enforcement } \\
\text { agency audits } \\
\text { with probability } \alpha\end{array}$
\end{tabular}

If parties decide not to produce information, occasional illegal transactions are not enforceable and all parties obtain zero payoffs. Consider now the non-trivial subgame in which the agents decide to produce hard evidence. We model the execution of the corrupt transaction taking place at $t=2$ as a sequential subgame that depends on the sequence of the exchange decided by the parties. In this and in the next section we discuss only one of the possible sequences in order to convey the main results of the model in the simplest possible way. In Section 4.2 we extend the analysis to a more general model.

Let us assume that the transaction subgame takes the form depicted in Figure 1. At the first node, $E_{0}$, the entrepreneur has two available actions: either to pay the bribe $(b)$, or not to pay it $(n)$. If she pays the bribe, the game moves to node $B_{0}$. At this node the bureaucrat has three available actions: denouncing the entrepreneur $(d)$; doing nothing $(n)$; and performing the action $(a)$. If the bureaucrat chooses $n$, the game reaches node $E_{1}$ where the entrepreneur can either denounce the bureaucrat 
$(d)$ or not $(n)$, and ends with the correspondent payoffs. If the bureaucrat performs $a$, the game gets to node $E_{2}$ where the entrepreneur has the same set of actions as in $E_{1}(d$ or $n)$. The payoffs are reported at the final nodes with the entrepreneur's payoff first and the bureaucrat's payoff second.

\section{Insert Figure 1 approximately here}

Participation. Both agents must find it in their interest to participate in the illegal transaction. For the entrepreneur we must have:

$$
(1-\alpha) v-b-\alpha F_{E} \geq 0 .
$$

This condition defines the maximum feasible value of the bribe $\bar{b}$ :

$$
b \leq \bar{b}=(1-\alpha) v-\alpha F_{E} .
$$

For the bureaucrat, the participation constraint with production of hard evidence is:

$$
(1-\alpha) b-\alpha F_{B} \geq 0
$$

which identifies the minimum feasible value of the bribe $\underline{b}$ :

$$
b \geq \underline{b}=\frac{\alpha}{1-\alpha} F_{B} .
$$

Since the participation constraints must hold even if the two agents could write a binding contract, we assume that $v>0$ is sufficiently large that - given the law enforcement parameters $\left(\alpha, F_{B}, F_{E}\right)$ - there exist some $b<v$, with $\underline{b} \leq b \leq \bar{b}$, at which the two participation constraints, $\left(\mathrm{PC}_{B}\right)$ and $\left(\mathrm{PC}_{B}\right)$, can be simultaneously satisfied. This implies $(1-\alpha) v \geq \alpha F_{E}+\frac{\alpha}{1-\alpha} F_{B}$.

Given the set $[\underline{b}, \bar{b}]$, the maximum gain for the entrepreneur is:

$$
M_{E}=v-\frac{\alpha}{1-\alpha} F_{B} .
$$

Considering the probability of conviction and the monetary sanction $F_{E}$, the entrepreneur's maximum expected gain, denoted by $\bar{M}_{E}$, is:

$$
\bar{M}_{E}=(1-\alpha) v-\alpha F_{E}-\frac{\alpha}{1-\alpha} F_{B} .
$$

Moreover, once the entrepreneur has paid the bribe (a sunk cost) her maximum expected gain becomes:

$$
\bar{M}_{E b}=(1-\alpha) v-\alpha F_{E} .
$$

Analogously, for the bureaucrat the maximum expected gain is:

$$
\bar{M}_{B}=(1-\alpha)^{2} v-(1-\alpha) \alpha F_{E}-\alpha F_{B} .
$$


Transaction implementation. The game is solved by backward induction, and the equilibrium concept used is that of Subgame Perfect Nash Equilibrium (SPNE).

Given the legal framework and the parameters of the LP (if any), agents can choose whether or not to produce hard evidence and the size of the bribe $b$ to facilitate the implementation of the occasional illegal transaction. Therefore, in the analysis of the basic model we will say that, given a leniency program, occasional corruption is implementable if there is one level of the bribe $b$ such that the game has a SPNE in which the bureaucrat performs the illegal action $a$, the entrepreneur pays the bribe $b$, and neither agent denounces the other.

Definition 2 An illegal transaction is implementable if the action profile $(a, b)$ is supportable in a Subgame Perfect Nash Equilibrium.

Conversely, we will say that corruption is not implementable when no such equilibrium exists.

\section{Analysis}

We characterize here the effects of leniency on one-shot corrupt transactions. As anticipated in the introduction, we will show here that badly designed MLPs may end up implementing otherwise unfeasible occasional illegal transaction by providing the first party that delivers with a credible threat - denouncing the corrupt deal to law enforcers - that forces the other party to comply. To be able to implement the illegal transaction with the threat of reporting, agents will produce hard evidence and use it as a "hostage", thereby incurring the risk of being detected by the law enforcement agency.

Consider first the benchmark case where there is no leniency, so that $S_{i}=R S_{i}$ $\left(R F_{i}=F_{i}\right)$ for all $i$. Then it is easy to verify that, whatever the value of $b$, the entrepreneur cannot credibly threaten to report the illegal agreement to the law enforcer if the bureaucrat does not deliver. If the entrepreneur retaliates against a defection from agreed strategies by reporting (choosing $d$ at node $E_{1}$ ), she will face the full sanction incurring an additional loss. Then, the bureaucrat's best action is $n$, i.e. keeping the gain from the partially executed illegal transaction without performing the action required by the illegal agreement. Knowing this, the entrepreneur will not enter into the illegal agreement in the first place. Note that this reasoning applies even when $F_{i}=0$. This proves the first, rather unsurprising result.

Proposition 1 Absent leniency programs, occasional sequential illegal transactions are not implementable.

To render an occasional illegal exchange implementable for some $b$, agents can use the hard evidence produced as a hostage, threatening to retaliate by reporting the hard information to law enforcers in case the second mover does not comply with the 
terms of the illegal agreement. For this mechanism to work, several conditions must be satisfied besides participation constraints.

The first condition regards the bureaucrat and it is a no-reporting condition. Respecting the agreement at the second node (choosing $a$ at $B_{0}$ ) must be weakly preferred to reporting (choosing $d$ ) and cashing the possible reward. This condition is:

$$
-R F_{B} \leq(1-\alpha) b-\alpha F_{B}
$$

The other two conditions regard the entrepreneur. The first can be called the credible threat condition. The reduced fine for the entrepreneur must be such that he can credibly threaten to report to the law enforcer (to choose $d$ at $E_{1}$ ) if the bureaucrat does not respect the agreement (choosing $n$ at $B_{0}$ ). This condition is:

$$
R F_{E} \leq \alpha F_{E}
$$

The second condition concerning the entrepreneur, also a no-reporting constraint, can be labelled the credible promise condition. The reduced fine for the entrepreneur must be such that he can credibly promise he will not report (he will not choose $d$ at $E_{2}$ ) if the bureaucrat obeys to the agreement at $B_{0}$. This condition is:

$$
-R F_{E} \leq(1-\alpha) v-\alpha F_{E} .
$$

All these conditions are summarized as follows:

$$
\left\{\begin{array}{c}
-R F_{B} \leq(1-\alpha) b-\alpha F_{B}, \quad \text { and } \\
-\alpha F_{E} \leq-R F_{E} \leq(1-\alpha) v-\alpha F_{E}
\end{array}\right.
$$

Consider now the effects of agents' ability to optimally set the bribe to facilitate the implementation of the illegal transaction. If necessary, agents can push the bribe up to $b=\bar{b}$ in order to make the illegal exchange implementable. The necessary and sufficient conditions that must be satisfied for a corrupt exchange being implementable are defined in the following Proposition.

Proposition 2 An occasional illegal transaction is implementable for some $b$ if and only if the following conditions are simultaneously satisfied:

$$
\begin{gathered}
-R F_{B} \leq \bar{M}_{B} \\
-\alpha F_{E} \leq-R F_{E} \leq \bar{M}_{E b} .
\end{gathered}
$$

The intuition for this result is very simple. If the conditions defined in the proposition hold, there is always a value of $b$ such that all relevant promises and threats are credible. In particular, the bureaucrat does not need to threaten the entrepreneur as he gets the bribe in any case. Therefore, the only relevant condition for the bureaucrat is that the LP is not so generous to lure him to cooperate with law enforcers even 
if the deal goes through. This obtains if the reduced sanction (possibly, the reward) $\left(-R F_{B}\right)$ is below the maximum expected gain he can derive from the illegal exchange $\left(\bar{M}_{B}\right)$. The two conditions regarding the entrepreneur guarantee that she can credibly threaten to report, if the bureaucrat does not perform $\left(R F_{E}<\alpha F_{E}\right)$, and credibly promise not to report if the bureaucrat does. For the entrepreneur the distribution variable, $b$, is irrelevant because once the bribe has been paid, she cannot recoup it in any case, so that the latter condition holds if $-R F_{E} \leq \bar{M}_{E b}$.

If we consider only MLPs we can state the following corollary of proposition 2 .

Corollary 1 Any $M L P$ such that $R F_{E} \leq \alpha F_{E}$ implements occasional sequential illegal transactions.

Proof. The definition of MLP guarantees that $-R F_{B} \leq \bar{M}_{B}$ and that $-R F_{E} \leq$ $\bar{M}_{E b}$. Hence proposition 2 applies if $R F_{E} \leq \alpha F_{E}$.

This corollary shows that a moderate leniency program creates the opportunity to undertake illegal transactions that would otherwise not be implementable when the reduced fine for the entrepreneur is lower than the expected fine.

All LPs that do not satisfy the conditions stated in Proposition 2 do not enforce occasional illegal transactions, if the game follows the sequence of moves described in the model. In particular, LPs that are sufficiently generous to reward a party above his/her maximum expected gain do not have this couterproductive side effect, and may have strong deterrence effects for illegal transactions sustained by repeated interaction, as explained in the next section.

\section{Generalization and extensions}

In this section we discuss several extensions of the basic model to verify the robustness of our conclusions to changes in modelling assumptions.

\subsection{Alternative sequences and general results}

In the previous sections we considered one possible sequence of the illegal exchange, the case where the entrepreneur pays the bribe before the bureaucrat's delivers the favor. Of course, in general parties can adopt several alternative timings to implement the illegal transaction. A general version of the game is depicted in Figure 2. At the first node the entrepreneur pays a portion $q$ of the bribe, then the bureaucrat decides whether to denounce the illegal agreement, perform $a$, or simply keep the portion of the bribe already cashed. In the latter two cases, the entrepreneur moves again and can pay the remaining portion of the bribe, $(1-q)$, if the bureaucrat has respected the agreement. In all cases the entrepreneur can report the illegal transaction to the law enforcer or do nothing. The bureaucrat has the same actions available at his following nodes. 
Insert Figure 2 approximately here

where:

$$
\begin{aligned}
& A=\left\{\begin{array}{cc}
0 & \text { if } q=0 \\
-q b-F_{E} & \text { if } q>0
\end{array},\right. \\
& B=\left\{\begin{array}{cc}
0 & \text { if } q=0 \\
-R F_{B} & \text { if } q>0
\end{array},\right. \\
& C=\left\{\begin{array}{cc}
0 & \text { if } q=0 \\
-q b-R F_{E} & \text { if } q>0
\end{array}\right. \text {, } \\
& D=\left\{\begin{array}{cc}
0 & \text { if } q=0 \\
-F_{B} & \text { if } q>0
\end{array},\right. \\
& E=\left\{\begin{array}{cc}
0 & \text { if } q=0 \\
-q b-\alpha F_{E} & \text { if } q>0
\end{array}\right. \text { ， } \\
& F=\left\{\begin{array}{cc}
0 & \text { if } q=0 \\
(1-\alpha) q b-\alpha F_{B} & \text { if } q>0
\end{array} .\right.
\end{aligned}
$$

The timing analyzed in section 3 assumes that $q=1$. In this section we first discuss the case in which $q=0$ and then show that parties cannot implement an illegal exchange by choosing an intermediate value of $q$ if the same transaction is not implementable either with $q=0$ or with $q=1$. Therefore, the union of the sets of LPs that implement the illegal transaction in one of the two extreme timings identify the entire set of LPs with counterproductive side effects.

Consider the alternative sequence in which $q=0$, as depicted in Figure 3. As for MLPs, by the same reasoning as in Section 3 is immediate that the necessary and sufficient conditions for the illegal transaction being implementable under this reversed sequence is $R F_{B}<\alpha F_{B}$. Given than agents can choose the sequence that allows them to implement their transaction, we can already say that for a MLP to implement the occasional illegal transaction it is sufficient that either $R F_{E}<\alpha F_{E}$, or $R F_{B}<\alpha F_{B}$.

\section{Insert Figure 3 approximately here}

More in general, the conditions under which a LP implements occasional illegal transactions under the reverse timing are the following.

Proposition 3 An occasional illegal transaction that follows the sequence defined by $q=0$ is implementable for some $b$ if and only if the following conditions are simultaneously satisfied: 


$$
\begin{gathered}
-R F_{E} \leq \bar{M}_{E} \text {; and } \\
-\alpha F_{B} \leq-R F_{B} \leq \bar{M}_{B} .
\end{gathered}
$$

Proof. Imposing the no-reporting condition for the entrepreneur and the credible promise condition for the bureaucrat, we get

$$
\left\{\begin{array}{c}
-R F_{E} \leq(1-\alpha) v-b-\alpha F_{E}, \text { and } \\
-R F_{B} \leq(1-\alpha) b-\alpha F_{B}
\end{array}\right.
$$

These conditions define the following bounds on $b$

$$
\left\{\begin{array}{c}
b \leq(1-\alpha) v+R F_{E}-\alpha F_{E}, \quad \text { and } \\
b \geq \frac{-R F_{B}}{1-\alpha}-\frac{\alpha}{1-\alpha} F_{B} ;
\end{array}\right.
$$

Considering the parties ability to set $b$ we need to identify those LPs such that there exist a value of $b \in[\underline{b}, \bar{b}]$ that lies beteween the bounds defined by $\mathrm{C}^{*}$. Hence, $\underline{b}$ must be not greater than the upper bound and $\bar{b}$ not lower than the lower bound. This leads to $-R F_{E} \leq \bar{M}_{E}$ and $-R F_{B} \leq \bar{M}_{B}$. The credible threat condition for the bureaucrat imposes $R F_{B} \leq \alpha F_{B}$ that identifies the third condition stated in the Proposition. This condition, together with $-R F_{E} \leq \bar{M}_{E}$ guarantees that the upper bound implied by $\mathrm{C}^{*}$ is not lower than the lower bound.

The (infinite) more complex alternative sequences of the transaction subgame in which the entrepreneur pays only a fraction $q \in(0,1)$ of the bribe at the beginning of the sequence of moves does not change the conditions in which a LP has counterproductive effects, as proved in the following complete characterization.

Proposition 4 The parties cannot implement an illegal transaction by choosing a $q \in(0,1)$ if the transaction is not implementable either with $q=1$, or with $q=0$. Therefore, a LP implements occasional illegal transactions if and only if either the conditions in Proposition 2 or the conditions in Proposition 3 are satisfied.

Proof. Consider the game descibed in Figure 2 and let the strategy of each player $i=E, B$, be denoted by a triple where the first element identifies the action chosen at node $i_{0}$, the second the action at node $i_{1}$ and the third the action at node $i_{2}$. The illegal transaction is implemented also if the entrepreneur pays only the first fraction of the bribe, provided that the bureaucrat chooses $a$ at $B_{0}$ and $n$ at the other nodes. Therefore two possible strategy profiles implement the illegal trasaction if they form a SPNE. The first one is $(q b, d, n)$ for the entrepreneur and $(a, n, n)$ for the bureaucrat. The second is $(q b, d,(1-q) b)$ for the entrepreneur and $(a, d, n)$ for the bureaucrat. The first profile is a SPNE if and only if

$$
-R F_{B} \leq(1-\alpha) q b-\alpha F_{B} \text { and }
$$




$$
-\alpha F_{E} \leq-R F_{E} \leq(1-\alpha) v-\alpha F_{E} .
$$

Note that if there is a LP that satisfies these conditions for a given $q$ the same LP satisfies these conditions for any $q^{\prime} \geq q$. Hence the set of LPs that allow the parties to implement the illegal exchange is the largest when $q=1$. The second profile is a SPNE if and only if

$$
\begin{gathered}
(1-\alpha) q b-\alpha F_{B} \leq-R F_{B} \leq(1-\alpha) b-\alpha F_{B} \text { and } \\
-\alpha F_{E} \leq-R F_{E} \leq(1-\alpha) v-\alpha F_{E}-(1-q) b .
\end{gathered}
$$

In this case if there is a LP that satisfies these conditions for a given $q$ the same LP satisfies these conditions for any $q^{\prime} \leq q$. Hence the set of LPs that allow the parties to implement the illegal exchange is the largest when $q=0$. This proves that, given a LP, the two parties cannot implement illegal transactions that would not be implementable either with $q=1$ or with $q=0$, by choosing an intermediate value of $q$.

The results of our model can therefore be summarized in simple economic terms as follows:

A LP does not implement occasional illegal transactions either if (a) it does not reduce the fine for either party below his/her expected full fine; or if (b) it grants a reward to at least one of the two agents above his/her maximum expected gain from the illegal transaction.

Condition a) implies that neither the entrepreneur nor the bureaucrat can credibly threaten to report the illegal transaction if the other party does not comply with the agreement. Condition $b$ ) guarantees that neither of the two agents can credibly promise not to inform the law enforcer at some point in time during the transaction. All other LPs implement occasional illegal transactions.

Meeting condition $a$ ) to avoid this side effect implies reducing the attractiveness of leniency for agents involved in long-term criminal relationships, which can be costly in terms of reduced deterrence. As pointed out by Spagnolo (2000, 2004), Buccirossi and Spagnolo (2001), and Aubert et al. (2004), well designed and managed LPs that generously reward self-reporting agents, as required by condition b), not only may eliminate the counterproductive side effects characterized in this paper; they may also substantially increase deterrence of dynamic criminal relationships sustained by repeated interaction. As mentioned in the introduction, "bounty schemes" that reward informants are not very common nowadays, most likely because they are not terribly appealing from an "ethical" and "social" perspective: "trust" and "cooperation" have a strongly positive connotation in most modern cultures, with little distinction on the objectives of such cooperation, while "snitches" and "informants" have very negative ones, even when they greatly increase social welfare. Of course rewards are not Nirvana, as mentioned in the introducion they could potentially generate other costs we abstract from in our model, particularly if they are poorly designed or inappropriately managed. However, they have been extensively and successfully used in the past, and are still in place in some advanced jurisdictions with respect to important crimes. The 
recent, successful US examples of the False Claim Act, providing substantial rewards to whistleblowers who file lawsuits against companies or individuals that defraud the government, and of the antitrust "Amnesty Plus" program, awarding a large reduction in a monetary fine due for a first convicted cartel (hence a large positive monetary reward) to cartel members that report information on an other not yet uncovered cartel, show how carefully designed and appropriately managed rewards schemes for whistleblowers can substantially improve the efficiency of law enforcement, with little or no side effects.

\subsection{Alternative mechanisms to implement an illegal exchange}

In the model discussed so far, absent a LP no occasional illegal transaction takes place. This of course does not imply that we are considering a world where, without LPs, there is no crime. Our obvious implicit assumption is that in any society there exist illegal transactions that do take place, for example because they are part of long term illegal relationships and can therefore be sustained/governed by repeated interaction or reputational concerns, and at the same time many potential occasional illegal transactions that cannot realize absent a LP. Our point is that, when LPs are introduced to deter the former forms of crime, if designed in certain ways they may at the same time help the latter forms of crime realize, with ambiguous total welfare effects. Fortunately there is no real trade-off: as mentioned at the end of the previous section, there are ways to both avoid the side effect and increase deterrence of long term illegal relationships.

It is interesting at this point to further extend the model and verify whether a LP can have counterproductive effects even on sequential illegal transactions that could in principle be implemented also without it. The implementation of a sequential illegal exchange requires an alternative governance mechanism to the LP that provides a credible threat to the agent that delivers first and that is subject to the opportunistic behavior of the coconspirator(s). For an illegal transaction a mechanism can be: a) the (infinite) repetition of this or analogous transactions; b) the provision of costly illegal "enforcement services" by a third party with commitment power; c) the direct threat of violence from one transacting party made credible by behavioral or reputational forces.

\subsubsection{Repetition}

As already mentioned, if the illegal exchange is not occasional but repeated with positive probability each period, agents can threaten to terminate their illegal cooperation in case one party behaves opportunistically. Folk theorems prove that if agents value future gains at a discount factor above a critical value the threat of the termination of the relationship suffices to implement the illegal transaction. An immediate corollary of our previous results is that, if the game we sketched does not change when repeated in time (e.g. with the accumulation of wealth by parties, or the increase in sanctions 
with the duration of crime), LPs that implement occasional illegal transactions also facilitate repeated illegal transactions making them implementable at any discount factor. This follows immediately from the repeated play of a Nash equilibrium in a stage game being always a SPNE of the infinitely repeated game originating from the repetition of that same stage game. This result already shows that a poorly designed LP may facilitate the implementation of illegal exchanges that could have been implemented through an alternative mechanism. ${ }^{11}$

More interestingly, Buccirossi and Spagnolo (2001, Theorem 1) show that even LPs that do not implement occasional (one-shot) illegal transactions may end up facilitating the enforcement of repeated ones. The intuition for this result is the following. In a repeated game, each agent confronts the short-term gains he could get by cheating on his partner (e.g. cashing the bribe without returning the favor), after which the illegal relationship breaks down, with the long-term gains he expects from continuing to respect the agreement and going on with the illegal relationship. A poorly designed LP may have the effect of stabilizing the relationship by reducing agents' short-term gains from deviation. This may happen because, if the first mover's threat to report in case his partners defects becomes credible (thanks to the LP), the second mover's optimal defection is not just running away with the money. If he does so, he triggers the opponent's threat, which in turn induces the law enforcer to intervene and impose a sanction on the deviator. His best deviation becomes instead abandoning the illegal relationship and self-reporting. If the LP is not sufficiently generous, i.e. if it does not reward sufficiently the informer, the short run gain from deviation becomes lower with the LP, whereas the punishment against an agent that defects and self-reports is the same as in the absence of a LP, since after one party defects and reports the relationship simply breaks down. Because short-run gains from defection decrease but losses from punishments do not, the LP loosens the second mover's incentive constraint and makes the illegal relationship sustainable at lower discount factors. ${ }^{12}$

On the other hand, in the same working paper it is also shown that a more generous LP, besides not helping to implement occasional transactions, has a much stronger deterrence effect on illegal exchanges sustained by the prospect of future interaction, confirming results in Spagnolo (2000-2004).

\subsubsection{Criminal enforcement services}

Some occasional illegal transactions are implemented thanks to the provision of illegal "enforcement services" by a criminal organization. Gambetta an Reuter (1995) argue that the stability of Sicilian cartels used to be guaranteed by the Mafia, a longliving organization sensitive to its reputation and therefore able and willing to commit

\footnotetext{
${ }^{11}$ Often, however, expected sanctions and damage claims change during a long term criminal relation, and in these cases this argument in this simple form does not apply.

${ }^{12}$ Again, for a complete characterization of LPs with counterproductive effects in repeated games we refer to our working paper, Buccirossi and Spagnolo (2001).
} 
to punish deviants harshly ex post. These services entail a cost for parties that (more or less willingly) "purchase" them, that also includes the expected sanction for collaborating with such a criminal organization. If we denote this cost with $c$, we have that absent a LP only those occasional illegal transactions with net present value $v \geq c$ are feasible. The introduction of a poorly designed LP may increase the number of feasible illegal transactions if the expected cost of using it strategically to implement the transaction is lower than $c$. This cost stems from the increased probability of being convicted given by the need to produce hard evidence, and is equal to $\alpha\left(S_{E}+S_{B}\right)$. Agents then will use the LP to implement only transactions such that $v \geq \alpha F_{B}+\frac{1}{1-\alpha} F_{E}$. Hence, if $\alpha F_{B}+\frac{1}{1-\alpha} F_{E}<c$ the LP facilitates illegal transactions even when a third-party enforcement service is present, otherwise, it does not.

\subsubsection{Direct violence}

If at least one of the two agents has an observable "preference for violent revenge", such that the utility he derives from punishing violently a former partner that "cheated" is larger than the cost of doing so, then an occasional sequential illegal transaction can easily be enforced by having this agent delivering first. Such a preference could either be a "real" (internalized) preference for reciprocity, or it can be due to a classic reputational concern of an agent planning to undertake other illegal transactions in the future.

This case is described by the game depicted in figure 4 where the entrepreneur has the possibility to retaliate against the bureaucrat at node $E_{1}$ with a violent action, $d v$ (not available in the previous version of the game), that gives her net utility $U$ and impose a loss $L$ on the bureaucrat, with $U, L>0$. Note that some assumptions are implicit in this description of the game. The first one is that some hard evidence is produced when parties agree to conclude the exchange. If producing hard evidence must be a joint decision, when parties have an alternative mechanism to implement their crime, they will choose not to produce the hard evidence, making the LP ineffective. The second assumption is that the game ends if the bureaucrat chooses action $d$ at node $B_{0}$, so that the entrepreneur cannot punish him if he deviates by reporting. This situation occurs if the bureaucrat is put under effective protection or if the first-moving revenge-loving agent is immediately sent to jail, so that the violent revenge is effectively prevented.

Obviously in this setting a LP cannot add anything to agents' ability to implement the occasional illegal transaction, as we are assuming that they have a costless way to implement it. Therefore, the only interesting question is whether a LP that could deter transactions implementable by this kind of violent threats may end up implementing other illegal transactions that would not be feasible otherwise. The answer to this question is no. The reason is that also in this case, in order to have deterrence effects, the LP must be sufficiently generous. This is because the decision of the bureaucrat to denounce the other agent is rational if and only if the LP leaves the 
bureaucrat better off relative to his maximum expected gain from not cheating in the transaction $\left(-R F_{B}>\bar{M}_{B}\right)$. In the reversed sequence, in which the bureaucrat moves first (assuming that he is the agent with a preference for violent revenge), the equivalent condition is $-R F_{E}>\bar{M}_{E}$. If both agents can credibly use violence at no cost and, therefore, can freely choose the timing of their moves, then the LP is effective if and only if both $-R F_{B}>\bar{M}_{B}$ and $-R F_{E}>\bar{M}_{E}$. All these LPs do not implement an occasional illegal transaction. Note also that this reasoning proves that MLPs do not help in fighting occasional illegal trasactions where agents have a costless way to implement it and may facilitate the implementation of other illegal deals.

\section{Insert Figure 4 approximately here}

We can conclude that a LP that implements an otherwise unfeasible occasional illegal transaction between wrongdoers without a preference for revenge would not be sufficiently generous to deter an illegal transaction sustained by a credible violent threat. Conversely, an LP sufficiently generous to deter an occasional sequential deal sustained by the threat of violence would not implement an occasional sequential deal between wrongdoers who cannot credibly threaten violent revenge. In other words, in this scenario where there exists a costless way to implement the illegal transaction a LP cannot make things worse. However, only correctly designed LPs that do not have counterproductive effects in other circumstances can be beneficial.

\section{Conclusions}

Within a stylized model we characterized the effects on the viability of occasional, sequential illegal transactions of all conceivable parametrizations of leniency policies for wrongdoers that spontaneously self-report to the law enforcing agency, turning in their partners.

The results highlight a risk involved in using moderate forms of leniency in law enforcement, forms that only cancel or reduce self-reporting parties' sanctions below the expected fine they would be subject to without reporting. Economists are aware that poorly designed incentive schemes may have counterproductive side effects, and leniency programs - as the law enforcement system in general - are incentive schemes. The moderate form of leniency often implemented around the world, while plausibly deterring some long-term criminal arrangements sustained by repeated interaction, may have a counterproductive side effect: it could be exploited by sophisticated wrongdoers to implement occasional illegal transactions that would not be feasible otherwise.

More generous forms of leniency that offer a reward to at least one party if he or she self-reports, if appropriately designed and managed, are not subject to this potential drawback and may further increase deterrence of long-term criminal relationships.

Enriching the model by introducing asymmetric information, uncertainty, mistakes in law enforcement, and other important features of reality we kept out of our 
model will surely modify the boundaries of our characterization, and it will be very interesting to understand in which direction. However, we are fairly confident that our qualitative conclusions will not change with future work. Leniency for wrongdoers that spontaneously self-report is a very powerful but also a potentially dangerous tool, that must therefore be properly designed and managed with care.

Aknowledgements. We thank Patrick Rey, two anonimous referees, and participants at the 2000 World Congress of the Econometric Society in Seattle for comments and suggestions. Usual caveats apply. Spagnolo aknowledges funding from the Swedish Competition Authority and the European Commission (EGEMTPS/RTN). 


\section{References}

[1] Aubert, Cecile; William Kovacic and Patrick Rey. "The Impact of Leniency Programs on Cartels," manuscript, 2004, IDEI Toulouse.

[2] Bardhan, Pranab. "Corruption and Development: A Review of the Issues," Journal of Economic Literature, Sept. 1997, 35(2), 1320-1346.

[3] Becker, Gary. "Crime and Punishment: An Economic Approach," Journal of Political Economy, Mar./Apr. 1968, 76(2), 169-217.

[4] Black, Bernard; Kraakman, Reiner, and Tarassova, Anna. "Russian Privatization and Corporate Governance: What Went Wrong?" Stanford Law Review, 52, 1731-1808, 2000.

[5] Boadway, Robin; Marceau, Nicolas, and Steeve Mongrain. "Joint Tax Evasion," Canadian Journal of Economics, Aug. 2002, 35(3), 417-435.

[6] Boycko, Maxim; Shleifer, Andrei, and Vishny, Robert. Privatizing Russia, 1995, Cambridge MA: MIT Press.

[7] Buccirossi, Paolo; Palumbo, Giuliana, and Giancarlo Spagnolo. "Whistleblowers and Financial Fraud", manuscript, 2005, Lear, Bank of Italy, and Stockholm School of Economics.

[8] Buccirossi, Paolo, and Giancarlo Spagnolo. "Leniency Policies and Illegal Transactions: How (not) to Fight Corruèption", Stockholm School of Economics Working Paper No. 451, 2001, available from www.swopec.se

[9] Buccirossi, Paolo (Ed.). Handbook of Antitrust Economics, forthcoming in 2006, Cambridge MA: MIT Press.

[10] Ellis, Christopher and Wilson, Wesley. "Cartels, Price-Fixing, and Corporate Leniency Policy: What Doesn't Kill Us Makes Us Stronger," manuscript, 2002, University of Oregon.

[11] Feess, Eberhard, and Markus Walzl. "Self-reporting in Optimal Law Enforcement When there are Criminal Teams," Economica 71, 2004, 333-348.

[12] Fiorentini, Gianluca, and Pelzman, Sam. (Eds.) The Economics of Organized Crime, 1995, Cambridge: Cambridge University Press.

[13] Gambetta, Diego and Reuter, Peter, "Conspiracy among the Many: The Mafia in Legitimate Industries," in Fiorentini, Gianluca, and Pelzman, SAm. (Eds.) 1995, 116-136. 
[14] Jones, Geraint; Hellman, Joel; Shankerman, Mark and Kaufmann, DAvid. "Measuring Governance, Corruption and State Capture: How Firms and Bureaucrat Shape the Business Environment in Transition," World Bank Working Paper 2312, April 2000.

[15] Harrington, Joseph E. JR. "Optimal Corporate Leniency Programs," manuscript, June 2005, Johns Hopkins University.

[16] Innes, Robert. "Remediation and Self-Reporting in Optimal Law Enforcement," Journal of Public Economics, June 1999a, 72(3), 379-393.

[17] Innes, Robert. "Self-Policing and Optimal Law Enforcement When Violator Remediation is Valuable," Journal of Political Economy, December 1999b, 107(6), 1305-1325.

[18] Innes, Robert. "Self-Reporting in Optimal Law Enforcement When Violators Have Heterogeneous Probabilities of Apprehension," Journal of Legal Studies, 29, 2000, 287-300.

[19] Innes, Robert. "Violator Avoidance Activities and Self-Reporting in Optimal Law Enforcement," Journal of Law, Economics \& Organization, Vol 17 (1), 2001, 239-56.

[20] Johnson, Simon; Mcmillan, John, And Woodruff, Christopher. "Property Rights, Finance and Entrepreneurship," NBER Working Paper No. 8852, March 2002.

[21] Kaplow, Louis, and Shavell, Steven. "Optimal Law Enforcement with Self-Reporting of Behavior," Journal of Political Economy, June 1994, 102(3), 583-606.

[22] Livernois, John, And C.J. McKenna. "Truth or Consequences. Enforcing Pollution Standards with Self-reporting" Journal of Public Economics 71, 1999, 415-440.

[23] Mauro, Paolo. "Corruption and Growth," Quarterly Journal of Economics, Aug. 1995, 110(3), 681-712.

[24] Mookherjee, Dilip, And I.P.L. Png. "Corruptible Law Enforcers: How Should They be Compensated?", Economic Journal, Jan. 1995, 105, 145-159.

[25] Motta, Massimo, and Polo, Michele. "Leniency Programs and Cartel Prosecution," International Journal of Industrial Organization, March 2003 , 21 (3), 347-379.

[26] Polinsky, Mitchell, and Shavell, Steven. "The Economic Theory of Public Enforcement of Law," Journal of Economic Literature, March 2000, 45-76. 
[27] Shleifer, Andrei, And Vishny, Robert. "Corruption," Quarterly Journal of Economics, Aug. 1995, 108(3), 599-617.

[28] Rey, PAtrick. "Towards a Theory of Competition Policy," in Advances in Economics and Econometrics: Theory and Applications, Eight World Congress, M. Dewatripont, L.P. Hansen S.J. Turnovsky eds., 2003 Cambridge University Press.

[29] Spagnolo, Giancarlo. "Optimal Leniency Programs," 2000a, F.E.E.M. Nota di Lavoro No. 42.00, Fondazione ENI Enrico Mattei, Milano (Available for download at http://www.ssrn.com/ and http://www.feem.it/).

[30] Spagnolo, Giancarlo. "Self-Defeating Antitrust Laws?," 2000b, F.E.E.M. Nota di Lavoro No. 52.00, Fondazione ENI Enrico Mattei, Milano (Available for download at http://www.ssrn.com/ and http://www.feem.it/).

[31] Spagnolo, Giancarlo. "Divide et Impera: Optimal Leniency Programs," December 2004, C.E.P.R. Discussion Paper No. 4840, (Available for download at http://www.cepr.org/).

[32] Spagnolo, Giancarlo. "Leniency and Whistleblowers in Antitrust", in BuCCirossi, Paolo (Ed.), Handbook of Antitrust Economics, forthcoming in 2006, Cambridge MA: MIT Press.

[33] Williamson, Oliver. "Credible Commitments: Using Hostages to Support Exchange," American Economic Review, Sept. 1983, 73, 519-40. 


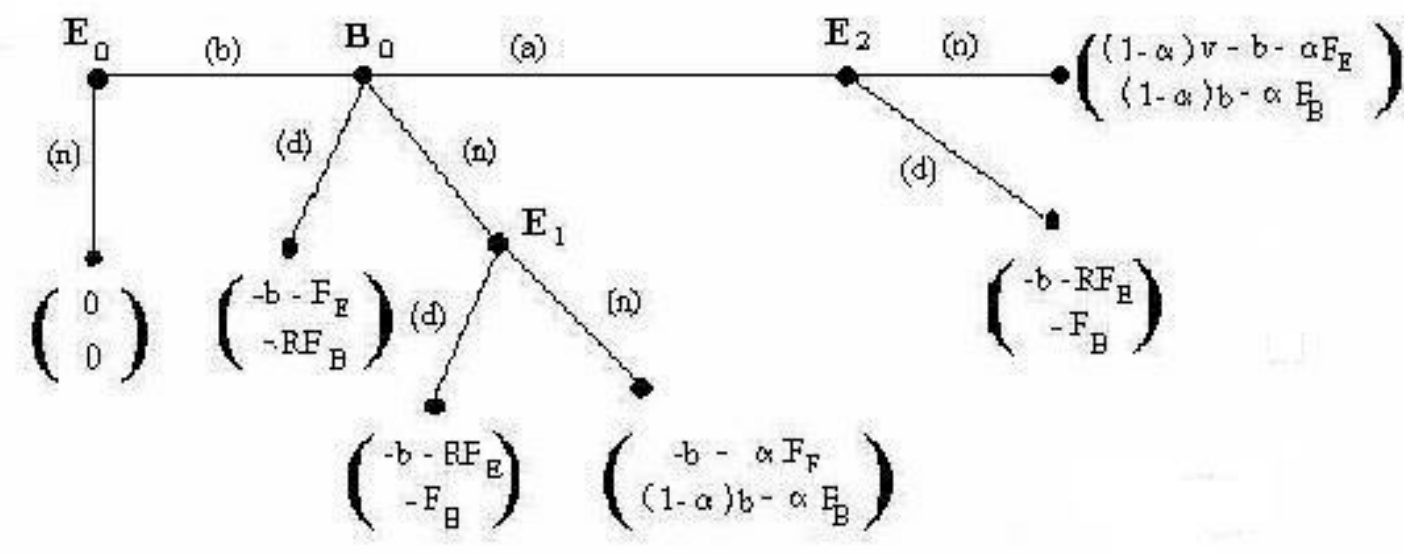

Figure 1: The illegal exchange

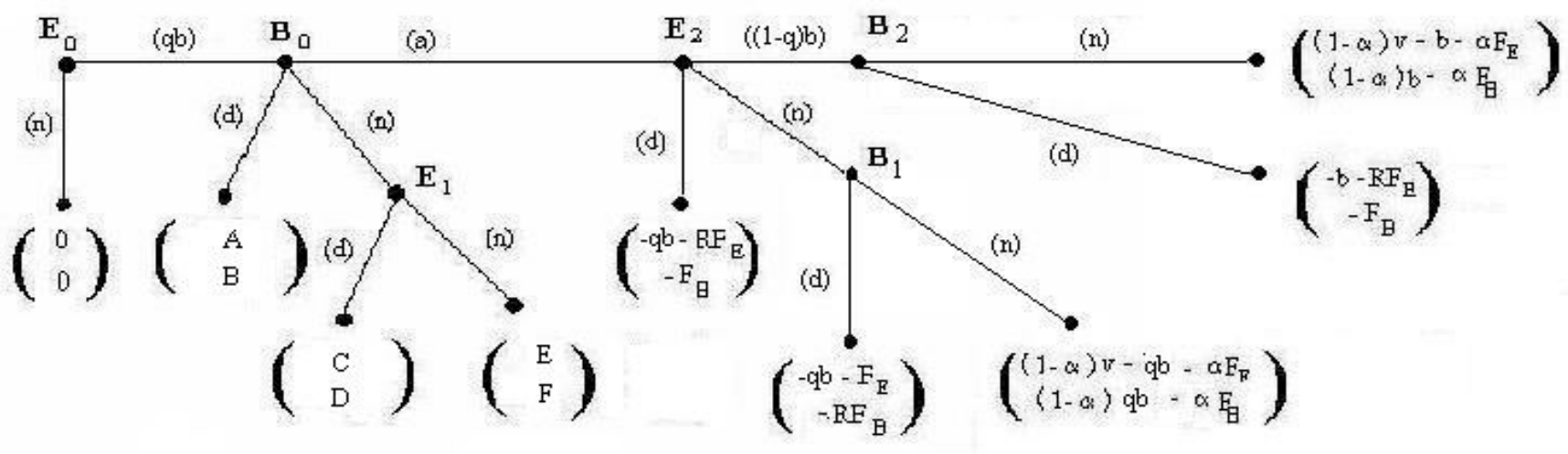

Figure 2: General version of the sequence of the illegal exchange 


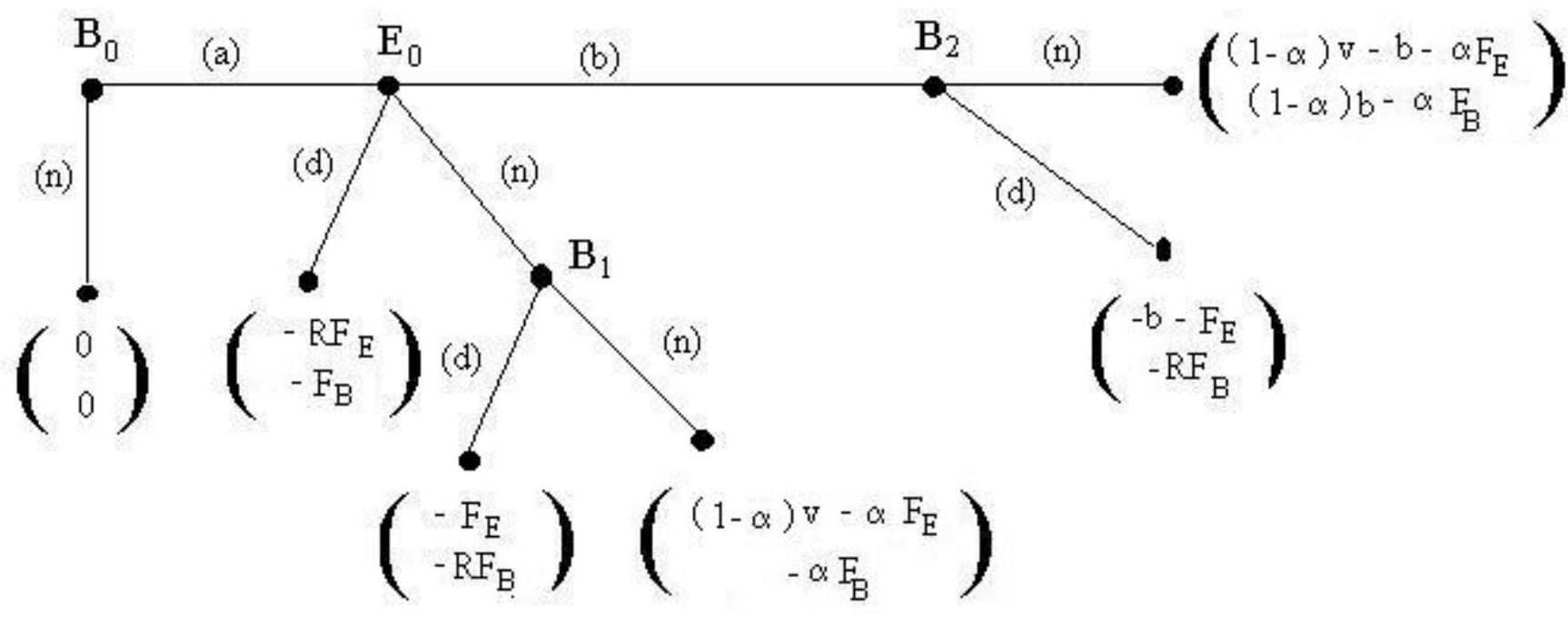

Figure 3: The illegal exchange with $q=0$

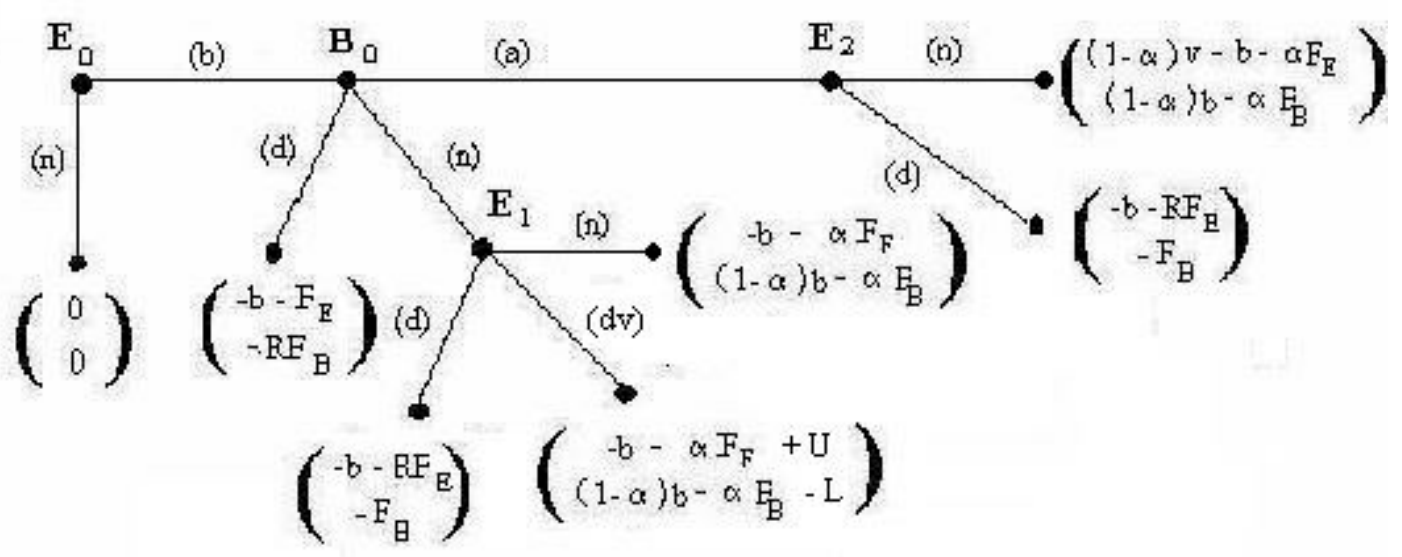

Figure 4: Illegal transaction with direct credible violence 